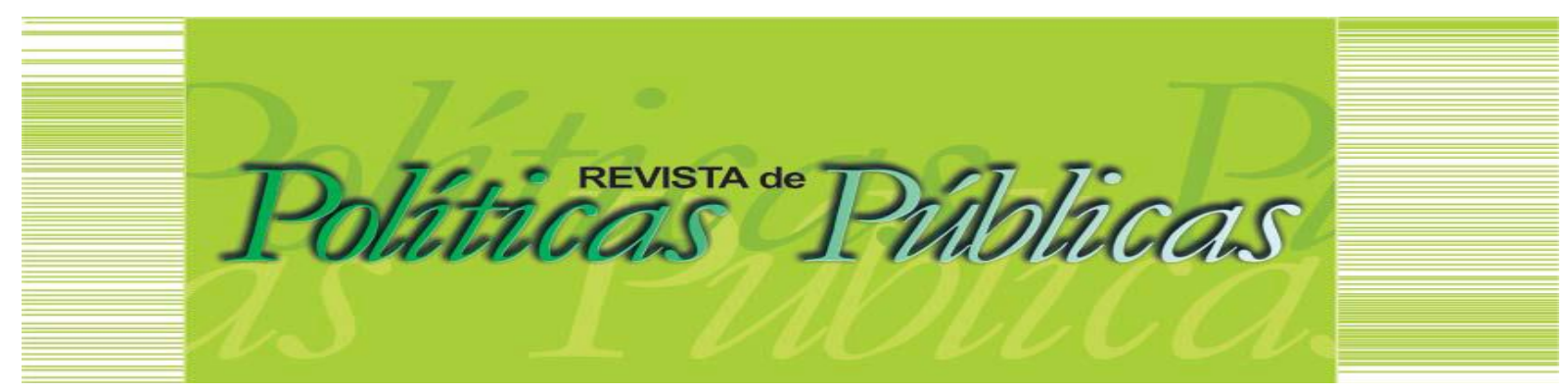

\title{
AS POLÍTICAS SOCIAIS NOS PLANOS DE GOVERNO DOS PRESIDENCIÁVEIS 2018 NO BRASIL E A MÍDIA
}

Juliana Cândido Matias ${ }^{1}$

Josemir Almeida Barros ${ }^{2}$

\begin{abstract}
Resumo:
A presente pesquisa teve como objetivo analisar e compreender o lugar das políticas sociais nos planos de governo apresentados pelos presidenciáveis nas eleições de 2018 no Brasil e o importante papel da mídia nesta interlocução. Após a análise dos planos de governo estabeleceram-se as categorias. Os três presidenciáveis que apareceram nos primeiros lugares nas pesquisas de intenção de votos foram considerados para a pesquisa, logo, os planos de Jair Bolsonaro (PSL), Fernando Haddad (PT) e Ciro Gomes (PDT) foram categorizados com o recurso do Software de análise de dados qualiquantitativos, "MaxQda". Muitas das categorias encontradas e sistematizadas estão vinculadas às Políticas Sociais i) habitação, direitos humanos, gênero, direitos trabalhistas, entre outros; ii) Saúde; iii) educação e iv) segurança. A categorização e análise dos planos evidenciaram a secundarização das Políticas Sociais em um dos planos, o que pode gerar perdas sociais históricas. Aportes teóricos a exemplo de Faleiros (2006), Secchi (2013) e reportagens de grandes mídias como BBC News, G1 e Folha de São Paulo online, também foram utilizados para nossas análises.
\end{abstract}

Palavras-chave: Políticas Públicas. Eleições 2018. Estado. Mídias.

\section{SOCIAL POLICIES IN THE GOVERNMENT PLANS OF THE PRESIDENTIAL HOPEFULS 2018 IN BRAZIL AND THE MEDIA}

\begin{abstract}
:
The present research aimed to analyze and understand the place of social policies in the government plans presented by the presidential candidates in the 2018 elections in Brazil and the important role of the media in this interlocution. After the analysis of the government plans, the categories were established. Jair Bolsonaro (PSL), Fernando Haddad (PT) and Ciro Gomes (PDT) plans were categorized with the use of the Software of analysis of qualitative data, "MaxQda". Many of the categories found and systematized are linked to Social Policies i) housing, human rights, gender, labor rights, among others; ii) Health; iii) education and iv) security. The categorization and analysis of the plans evidenced the secondation of Social Policies in one of the plans, which can generate historical social losses. The theoretical contributions such as Faleiros (2006), Secchi (2013) and reports of major media such as BBC News, G1 and Folha de São Paulo online, were also used for our analyzes.
\end{abstract}

Kewords: Public Policies. Elections 2018. State. Media.

Artigo recebido em: 11/12/2018 Aprovado em: 06/04/2019 DOI: http://dx.doi.org/10.18764/2178-2865.v23n1p339-355

\footnotetext{
1 Pedagoga. Mestra em Educação. Professora das redes Estadual e Municipal de Rolim de Moura/RO. Endereço: Avenida Curitiba, 4447-Centro, Rolim de Moura. E-mail: juhmatias.rm@gmail.com

2 Historiador e Pedagogo. Doutor em Educação. Professor pela Universidade Federal e Rondônia (UNIR). Endereço: Av. Pres. Dutra, 2967 - Olaria, Porto Velho. E-mail: josemir.barros@unir.br
} 


\section{INTRODUÇÃO}

As políticas sociais sofreram transformações históricas, seja na forma de serem pensadas e/ou implementadas pelo Estado, e muitas vezes são gestadas em consonância ao modo de produção capitalista e suas relações de poder, que abarcam os mais variados âmbitos da sociedade e suas maneiras de ter, ser e viver.

Assim, como item preconizado à pauta eleitoral, as políticas sociais são usadas pelos candidatos a cargos no executivo como propagandas de governo, seja em palanques e/ou meios de comunicação em geral ${ }^{1}$, o que, em alguns casos, não condiz com as propostas e planejamento apresentados em seus planos de governo, logo, o tema precisa ser compreendido e analisado por causa de seu importante papel e contradição nos discursos políticos e eleitorais no Brasil, e sua intrínseca relação com os interesses de mercado.

Compreender essa relação do lugar das políticas sociais nos planos de governo apresentados pelos presidenciáveis e o papel das mídias nesse processo de interlocução, requer critérios essenciais para garantir uma análise mediante a polifonia das redes sociais e dos meios de comunicação neste ínterim. A partir deste objetivo, categorizamos os planos de governo dos presidenciáveis das eleições de 2018 que apareceram nos primeiros lugares nas pesquisas de intenção de votos pelas principais empresas de consultoria eleitoral: Datafolha Instituto de Pesquisa ${ }^{2}$ e IBOPE Inteligência ${ }^{3}$, logo, os planos de Jair Bolsonaro (PSL), Fernando Haddad (PT) e Ciro Gomes (PDT). A categorização dos planos de governo dos presidenciáveis foi feita com o recurso do Software de análise de dados qualiquantitativos, o MAXQDA4. As categorias foram divididas a partir do eixo políticas sociais: i) habitação, direitos humanos, gênero, direitos trabalhistas, entre outros; ii) Saúde; iii) educação e iv) segurança.

A categorização e análise dos planos possibilitaram a formulação dos mapas visuais demonstrativos sobre como as propostas de políticas sociais aparecem nos planos de governo dos presidenciáveis; evidenciaram que, em alguns planos de governo, as propostas e planejamento das políticas sociais são mais contemplados em relação a outros, o que pode gerar perdas sociais históricas e até mesmo irreversíveis ao efetivar no pleito eleitoral de 2018 essa escolha. Aportes teóricos a exemplo de Faleiros (2006), Secchi (2013), bem como reportagens de mídias como BBC News, G1 e Folha de São Paulo online, foram utilizados para nossas análises.

\section{POLÍTICAS PÚBLICAS E SOCIEDADE: a interface hegemônica do Estado}

A maneira como as políticas públicas são pensadas e implementadas sofreu, historicamente, significativas transformações. Embora ainda tenha em sua totalidade 0 atendimento a demandas sociais, a forma como essas políticas acontecem tem exemplificado os propósitos e os 
ideais de agentes públicos em contextos diversos, os fins de cada uma, bem como seus atores, já não são ponderados como em décadas passadas, o que para Secchi $(2013$, p. 2) significa dizer que:

[...] uma política pública é uma orientação à atividade ou à passividade de alguém; as atividades ou passividades decorrentes dessa orientação também fazem parte da política pública; uma política pública possui dois elementos fundamentais: intencionalidade pública e resposta a um problema público; em outras palavras, a razão para o estabelecimento de uma política pública é o tratamento ou a resolução de um problema entendido como coletivamente relevante.

Nota-se que além dos dois elementos citados por Secchi (2013), intencionalidade pública e resposta a um problema público, o elemento passividade nos remete em sua acepção de continuidade a uma determinada forma de pensar e fazer a política pública sem avaliações sobre 0 público a que se destina; já o que se refere a atividades, corresponde a políticas para manutenção e/ou promoção de bem-estar da população que esteja fora do mercado de trabalho, garantindo, assim, a regulamentação do mercado e seu sistema capitalista.

A consolidação do capitalismo ${ }^{5}$, as revoluções (industrial, burguesas entre outras), 0 avanço da industrialização dos meios de produção em toda a sua recente tecnologia, e também as grandes guerras: Primeira Guerra Mundial (1914-1918) e a Segunda Guerra Mundial (1939-1945) contribuíram para que as políticas públicas se reestruturassem a atender tanto às demandas sociais, quanto a manter os interesses do mercado, pois "[...] dependendo do tipo de política pública que está em jogo, a estruturação dos conflitos, das coalizões e o equilíbrio de poder se modificam." (SECCHI, 2013 , p. 16). Assim como em um jogo de cartas marcadas, as políticas públicas se tornaram valiosas e passíveis de serem implementadas conforme a concepção de Estado e as políticas vigentes, ou a falta delas.

À mercê das variadas categorias de atores ${ }^{6}$, as políticas públicas têm se configurado cada vez mais um fator decisivo para deliberações do Estado no que se refere à sociedade, economia, educação e, por consequência, em alguns casos, uma moeda de troca para campanhas políticas, políticas de governo e alvo de planos de gerenciamento de Estado, que no Brasil tem por tradição o viés liberal. Um dos exemplos é o plano Bresser dos anos $1990^{7}$ que, na promessa de uma administração gerencial, trouxe uma proposta explícita de Estado mínimo acompanhada de emendas constitucionais para a reforma administrativa e da previdência, bem como a instabilidade do funcionalismo público em detrimento da meritocracia. Tudo isso evidencia a capacidade governamental de manipulação das políticas públicas para os interesses do Estado, subvalorizando a sua gênese em atender as demandas sociais.

O traçado das políticas públicas e sua indissociabilidade às formas de Estado trazem à tona uma importante questão: afinal, o que é política social? Em meio a tantas tramas e vieses, a questão social das políticas públicas corre o risco de ficar subentendido caso não se aprofunde em 
seus nós conceituais, dada a sua complexidade; todavia, Faleiros (2006), estabelece o tom dessa trama, tornando-a mais compreensível.

As políticas sociais ora são vistas como mecanismos de manutenção da força de trabalho, ora como conquistas dos trabalhadores, ora como arranjos do bloco no poder ou bloco governante, ora como doação das elites dominantes, ora como instrumento de garantia do aumento da riqueza ou dos direitos do cidadão. (FALEIROS, 2006, p. 8).

Assim, levar em conta os contextos históricos em que é implementada uma política social é primordial, para que não se caia no conto da bondade ilusória, pois ainda de acordo com Faleiros (2006, p. 12) "[...] através dessas medidas, o Estado e os políticos aparecem como bons para o povo, preocupados com sua situação social [...]." Tudo isso, à luz da história, não se configura como particularidades; são perceptíveis na história da sociedade brasileira as idas e vindas para a consolidação da cidadania e, consequentemente, a garantia dos direitos sociais. Muitos foram, são e serão os discursos e pautas das agendas diárias dos candidatos a cargos públicos na condição de presidenciáveis do Brasil que nos remetem a favores.

Os serviços educacionais, de orientação social, de assistência médica, de ajuda jurídica e outros compõem um conjunto importante de atividades oferecidas pelas instituições sociais [...]. Esses auxílios e serviços, mesmo garantidos por lei, geralmente aparecem como favores à população. (FALEIROS, 2006, p. 12).

Assim, Faleiros (2006) vai ao cerne da questão das políticas sociais, pois evidencia uma oportuna discussão acerca de como são vistas pelo senso comum, e o quanto interferem na aprovação ou reprovação de determinado governo. Alternando-se entre o necessário e o midiático, essas políticas são determinantes para garantir a ordem e a passividade social, para que os interesses do capital possam imperar sem grandes agitações sociais, causando demasiado prejuízo às mais variadas instâncias da sociedade. As políticas públicas deveriam surgir por meio da institucionalização de problematizações advindas da própria sociedade, foco das ações; não por políticas de governo que são abruptamente cerceadas e prometidas a cada eleição, independentemente de serem positivas ou não à população.

Há de se ponderar, nessa conjectura, os tons das políticas públicas ao redor do mundo, mas para uma análise mais pontual é necessário vislumbrar como são pensados pelo avanço do capitalismo em países periféricos, como sofrem influência pela forma de Estado adotada e, principalmente, como é a reação estatal frente às políticas públicas em tempos de crise do capitalismo ente outros territórios, e não apenas no Brasil.

Pensar políticas públicas, bem como as políticas sociais e sua estreita relação com 0 Estado requer um olhar para além dos muros, para que se veja, interprete e analise a ligação extrema entre as formas de se fazer essas políticas junto aos interesses das relações de poder globalizadas, conservadoras e excludentes. Não há ações políticas isoladas, e sim algumas teias interligadas pelas 
necessidades do mercado capitalista, para que seja mantido em toda a sua estrutura, garantindo 0 lucro e a produtividade a qualquer custo, principalmente na imposição à adoção de cortes orçamentários públicos destinados à educação, saúde, previdência, trabalho entre outros. Cortes financeiros estabelecidos por meio das proposições dos agentes públicos no formato das reformas. A perversa estrutura de convencimento da contenção de gastos públicos sociais por meio do reforço da ideologia burguesa se faz presente em diversos espaços; seja nas propagandas midiáticas dos presidenciáveis, nos discursos proferidos em palanques ou até mesmo na apresentação de reformas, como a da previdência, estabelecida como o foco prioritário.

Foi assim que surgiu, ao final da segunda guerra (1945), o Estado de bem-estar social, ou Welfare State, mencionado por Faleiros (2006), que corresponde ao acesso a bens e serviços sociais e que está articulado ao desenvolvimento do capitalismo, ou seja, todos teriam acesso mínimo aos serviços básicos de subsistência para que o caos não se instaurasse nas entranhas da sociedade. Destarte, este não é/foi o caso de países periféricos que dependem "[...] de programas criados a cada gestão governamental, segundo critérios clientelísticos e burocráticos." (FALEIROS, 2006, p. 28). Constatamos o esforço de candidatos a cargos no parlamento (executivo) para a manutenção do mínimo para se viver, expondo a miséria humana a características desumanas; esse fator nos alerta novamente para os possíveis prejuízos dos trabalhadores que sempre pagam mais sobre o preço das reformas (previdência), ou seja, tomam prejuízos significativos.

Se nos delineamentos desse meandro político e econômico já se enxerga a exploração estrutural do capital em detrimento do humano em toda a sua relação histórica, é possível pensar que essa relação se torna ainda mais miserável à medida que as crises do capitalismo se agravam. Eis que, então, a sua interface mais cruel é instigada.

As políticas sociais não são formas estáticas de relação entre Estado e sociedade. Os neoliberais propõem, nos períodos de crise, a extinção das medidas sociais e a volta ao mercado de trabalho, sem proteção do Estado, e isto justamente num momento em que os trabalhadores estão mais vulneráveis pela desmobilização decorrente do desemprego e da procura de emprego. (FALEIROS, 2006, p. 79).

Desse modo, fica evidente o quanto as políticas sociais são manipuláveis de acordo com os poderes políticos e econômicos, e que, embora tenha em sua origem a atenção às demandas sociais, na ponta do lápis a escrita é outra. Além de instáveis e assistencialistas, as políticas sociais são as primeiras a sofrerem cortes quando o capitalismo entra em crise, pois além de cultivar a sociedade em classes, muito interessa aos Estados liberais a perpetuação dessas classes, geração após geração, em que os filhos ocupem sistematicamente o lugar de seus pais no chão das fábricas, e posteriormente, seus netos, num ciclo hegemônico propositalmente interminável a partir do projeto burguês de sociedade. 
É nesse contexto que as políticas sociais são planejadas e implementadas, ou não: à sorte das predileções do capitalismo, ao qual servem com maestria, juntando-se à teia estrutural das políticas econômicas, sociais e convenientemente educacionais, pensadas a partir das necessidades do mercado e implementadas mediante os interesses do Estado vigente, o que justifica a necessidade de serem analisadas dentro das propostas de governo dos presidenciáveis no último pleito eleitoral de 2018 no Brasil, que ocuparam os primeiros lugares nas pesquisas de intenção de voto ao longo do período eleitoral, entre os meses de agosto a outubro de 2018.

\section{ELEIÇÕES PRESIDENCIAIS 2018, A POLIFONIA MIDIÁTICA E A CONJUNTURA SOCIAL}

As eleições presidenciais do ano de 2018 no Brasil foram marcadas por grande polarização dos/nos discursos políticos e midiáticos: em alguns debates ${ }^{8}$ em redes de televisão, rádios, redes sociais, revistas, entre outros. Diversas pesquisas de opinião feitas e divulgadas por instituições especializadas, a exemplo da DATFOLHA e IBOPE, foram divulgadas pelos meios de comunicação de formas variadas; e embora divulgassem resultados semelhantes ${ }^{9}$ das pesquisas de opinião, utilizavamse de elementos discursivos ${ }^{10}$ variados para convencer os eleitores e leitores de notícias veiculadas a partir de seus propósitos, conforme os interesses de cada fonte.

Concorreram à presidência do Brasil no ano de 2018, treze candidatos e candidatas de diversos partidos políticos, alguns já conhecidos, outros novos.

\section{Quadro1 - Candidatos e candidatas à presidência da república em 2018}

\begin{tabular}{|l|c|}
\hline CANDIDATO/ CANDIDATA & PARTIDO \\
\hline Álvaro Dias & PODEMOS \\
\hline Cabo Dacilolo & PATRI \\
\hline Ciro Gomes & PDT \\
\hline Eymael & DC \\
\hline Fernando Haddad & PT \\
\hline Geraldo Alckimin & PSDB \\
\hline Guilherme Boulos & PSOL \\
\hline Henrique Meireles & MDB \\
\hline Jair Bolsonaro & PSL \\
\hline João Amoedo & NOVO \\
\hline João Goulart Filho & PPL \\
\hline Marina Silva & REDE \\
\hline Vera & PSTU \\
\hline
\end{tabular}

Fonte: GAZETA DO POVO. Eleições 20108: candidatos a presidência do Brasil. Curitiba, 2018. Disponível em: https://especiais.gazetadopovo.com.br/eleicoes/2018/candidatos/presidente/. Acesso em: 7 out. 2018.

Os candidatos e candidatas disputaram durante o período eleitoral, além do cargo de maior representatividade política brasileira no executivo, as atenções dos principais meios de 
comunicação e das mídias sociais, o que se mostrou um grande desafio frente a maior onda Fake News ${ }^{11}$ da história das eleições no Brasil.

As Fake News, facilmente propagadas pelas redes sociais sem nenhum compromisso com fontes e/ou pesquisas científicas, geraram uma grande entropia nos processos comunicativos entre os eleitores, abarcando todo tipo de senso comum sem ligação alguma com o que se propagava, possibilitando discussões acaloradas e, em alguns casos, violentas, como salientado pela BBC News Brasil (2018) em sua reportagem Fake news nas eleições de 2018: Um Brasil dividido e movido a notícias falsas, uma semana dentro de 272 grupos políticos no WhatsApp em que a jornalista Juliana Gragnani (2018) pôde, por meio da pesquisa, observar a rapidez incontrolável da propagação das Fake News, ou seja, notícias falsas que confundiram os eleitores em ambos os lados da polarização política recente.

Os criadores de notícias falsas se apropriaram e alteraram os formatos de notícias reais para respaldar, disseminar e confundir, por meio de mentiras, quem as utilizava como referências; tanto os receptores dos meios tradicionais de comunicação quanto outros. Utilizando-se de áudios e montagens de capas e reportagens de diversas revistas brasileiras, essas notícias, ao serem repassadas/disseminadas por pessoas próximas, angariam confiabilidade, sem a necessidade de checagem da veracidade das fontes. Constitui-se a história de uma verdade absoluta por meio das Fake News.

A reportagem intitulada Aliados pressionam Haddad para que ele abandone a agenda 'Lula Livre'; Bolsonaro reforçará discurso anti-PT feita pelo G1 (SADI, 2018), uma das maiores fontes de notícias online brasileira, ligada ao grupo da rede Globo de televisão, ao abordar o segundo turno entre os candidatos Fernando Haddad e Jair Bolsonaro, traz:

Faltava combinar com o ex-presidente Lula, com quem Haddad se encontrou nesta segunda-
feira (8), e com o comando do PT, que vetou mudanças ao centro no primeiro turno, como
queria o grupo mais ligado a Haddad, para ampliar apoios. Sem contar que aliados de
Haddad, seu grupo mais próximo, pressionam o candidato para que ele abandone a agenda
'Lula Livre', como apelidaram nos bastidores as declarações de que a prisão de Lula -
condenado por corrupção - foi uma injustiça. (SADI, 2018).

A reportagem evidencia questões estruturais dentro da conjuntura política e partidária da candidatura de Haddad e sua busca por alianças, enquanto reforça a sua ligação com o ex-presidente Luiz Inácio Lula da Silva, enfatizando sua condenação, estabelecendo, assim, o direcionamento proposital para os receptores. Quanto ao candidato Bolsonaro que, segundo a reportagem, teria como estratégia de candidatura e foco político o antipetismo ${ }^{12}$, a jornalista cita inclusive seu vice, e enaltece sua proposta, fazendo menção ao partido de Haddad, relacionando-o novamente à palavra corrupção.

Na campanha de Bolsonaro, o general Hamilton Mourão, candidato a vice, disse ao blog que 'faltou pouco' para o primeiro turno e que agora era questão de 'afinar ponteiros'. 0 tom da 
campanha no segundo turno será reforçar o anti-petismo, vinculando Haddad a escândalos de corrupção do partido dos trabalhadores. (SADI, 2018).

Já o jornal Folha de São Paulo online (2018), em seu site, trouxe a reportagem de Igor Geilow, Bolsonaro e Haddad se enfrentarão no segundo turno, e de maneira clara aproveitou-se do ensejo para tecer uma crítica ao então presidente Michel Temer enquanto expõe a rejeição aos dois candidatos ao segundo turno da presidência do Brasil.

Se de 1994 a 2004 o que estava em jogo era avalizar ou rejeitar a gestão anterior, agora tanto Bolsonaro quanto Haddad são opositores ferrenhos da agônica e impopular presidência de Michel Temer (MDB). 0 segundo turno, porém, vai se dar entre os candidatos de maior rejeição pelo eleitorado. (GIELOW, 2018).

Essa polifonia das grandes mídias reflete os variados sons/tons a que chegaram as informações relacionadas à eleição presidencial 2018 no Brasil. Em meio à imensa elaboração e propagação de Fake News, para grupos de WhatsApp, Facebook e Sites, as informações geradas propositalmente com interesses encomendados diante do contexto político e suas relações de poder fizeram com que os debates sobre as políticas sociais se tornassem coadjuvantes no cenário, sendo diminuídas e até subtraídas, marginalizadas nas postagens e veiculações sobre os presidenciáveis. Diante desse contexto, como pensam sobre as políticas sociais em seus planos de governo os presidenciáveis que ocuparam os primeiros lugares no pleito eleitoral de 2018?

\section{AS POLÍTICAS SOCIAIS NOS PLANOS DE GOVERNO DOS PRESIDENCIÁVEIS LÍDERES NAS PESQUISAS}

As políticas sociais são a base para as respostas às demandas sociais em suas diferentes estruturas historicamente estabelecidas. Assim, os planos de governo dos presidenciáveis tenderam a expor seu planejamento prévio para que as necessidades da sociedade pudessem ser atendidas e contempladas, mesmo como políticas de governo, na objetivação do viés de cada plano/candidato/partido/coligação.

De modo geral, vislumbravam-se melhorias nas condições de vida, ao tratarmos de políticas públicas no que tange à saúde, educação, segurança, ou seja, suas ações na condição de políticas sociais: previdência social, trabalho e direitos trabalhistas, moradia e habitação, equidade racial e de gênero, entre outros.

Reverter os impostos pagos pelo trabalhador em bens e serviços comuns gerenciados pelo Estado é de suma importância para a diminuição de índices de mortalidade infantil, analfabetismo e criminalidade, ou seja, situações de risco à população.

Avanços são notados historicamente no Brasil nesse ínterim ${ }^{13}$, todavia essa conjuntura tem desvelado um terreno em crise, em que os programas sociais são sistematicamente 
marginalizados pelo senso comum com o incentivo das diversas mídias que multiplicam informações, sem necessariamente conferir a(s) fonte(s) e a(s) fidedignidade(s) do(s) fato(s), gerando um descrédito sobre as políticas sociais que desoneram paulatinamente o Estado de sua obrigatoriedade legal, ocasionando, assim, um esvaziamento de debates sobre o que de fato corresponde a um governo com propósitos para a burguesia à custa dos trabalhadores.

Nesse interregno, como se compreende as políticas sociais apresentadas pelos presidenciáveis das eleições de 2018 no Brasil, por meio de seus planos de governo? Foi possível analisar essa conjuntura através da categorização dos planos de governo dos primeiros presidenciáveis apontados pelas principais empresas de pesquisa de opinião e/ou consultorias brasileiras que há décadas divulgam consultas e possíveis resultados das eleições, como 0 DATAFOLHA e o IBOPE.

A utilização do software MAXDQA foi importante para o trabalho de identificação, sistematização e auxílio na categorização dos dados coletados. O aporte de materiais teóricos e metodológicos permeou todo o processo para externar as diretrizes sobre o método científico. A investigação foi dividida em etapas: no primeiro momento recorreu-se às leituras de cada programa de governo; na etapa seguinte, a cuidadosa identificação e análise dos itens e/ou fragmentos de textos que abordavam o eixo fundante, que corresponde às políticas públicas em seus desdobramentos na condição de políticas sociais. Por fim, os dados identificados por meio de itens e/ou fragmentos de textos foram codificados, cruzados e transformados em mapas visuais, contendo as categorias de análises e suas respectivas incidências em cada um dos programas de governo.

[...] cada conjunto de dados pode ser codificado de acordo com mais de uma categoria de codificação extraída de mais de uma família de codificação. As famílias de codificação apresentadas deverão proporcionar-the alguns instrumentos para o desenvolvimento de categorias de codificação que the serão uteis na classificação dos seus dados. (BOGDAN; BIKLEN, 1994, p. 222).

O estabelecimento das categorias de análises sobre as políticas públicas externou as divergências entre os programas de governo e reforçou a defesa de uma concepção de Estado.

Em síntese, a categorização dos planos de governo dos presidenciáveis foi feita com 0 recurso do Software de análise de dados qualiquantitativos, o MAXQDA. As categorias foram divididas em: políticas sociais i) habitação, direitos humanos, gênero, direitos trabalhistas, entre outros; ii) Saúde; iii) educação e iv) segurança. A categorização dos planos de governo possibilitou a formulação dos mapas visuais demonstrativos sobre como as propostas de políticas sociais aparecem nos planos de governo dos presidenciáveis.

Figura 1 - Resultado sistemático das pesquisas da eleição presidencial pelo DATAFOLHA de abril a setembro de 2018 


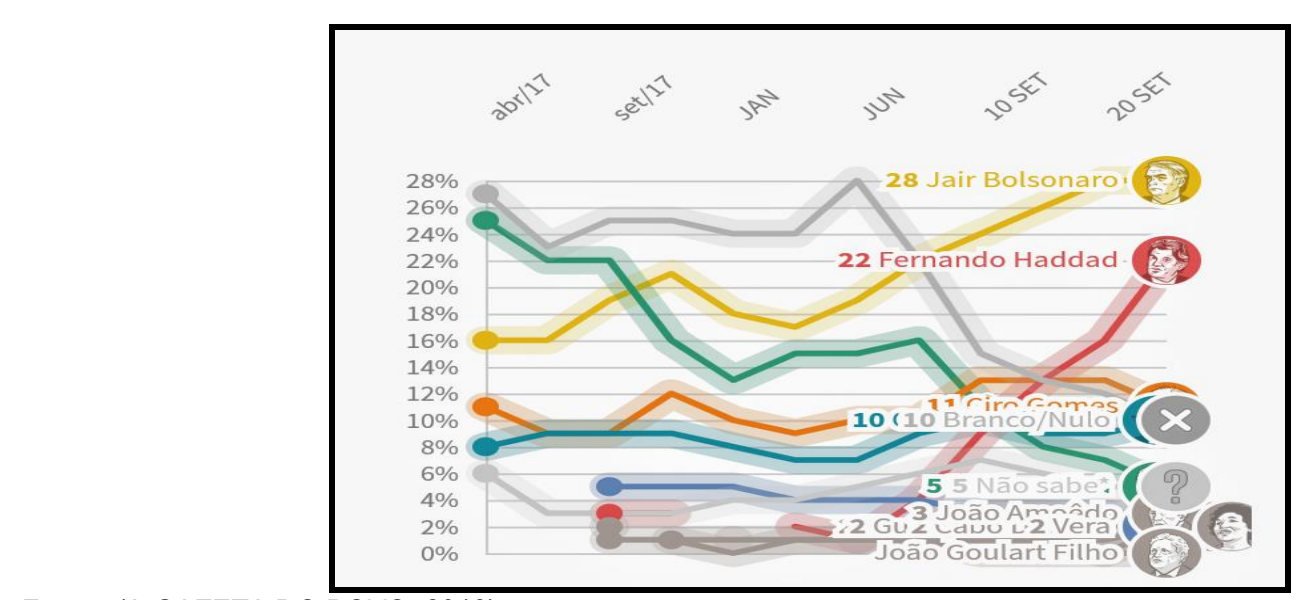

Fonte: (A GAZETA DO POVO, 2018).

A Figura 1 evidencia um início das eleições demasiado improvável: os votos brancos e nulos e os que não sabiam em quem votar somavam os primeiros lugares no gráfico, enquanto 0 presidenciável do PSL assegurava o terceiro lugar na disputa, subindo nas pesquisas de modo significativo somente a partir do primeiro semestre de 2018 , terminando o pleito com uma diferença de seis pontos para o segundo candidato, Fernando Haddad, e 17 pontos para o terceiro colocado, Ciro Gomes.

Figura 2 - Resultado sistemático das pesquisas da eleição presidencial pelo IBOPE de agosto a setembro de 2018

Fonte: (A GAZETA DO POVO, 2018).

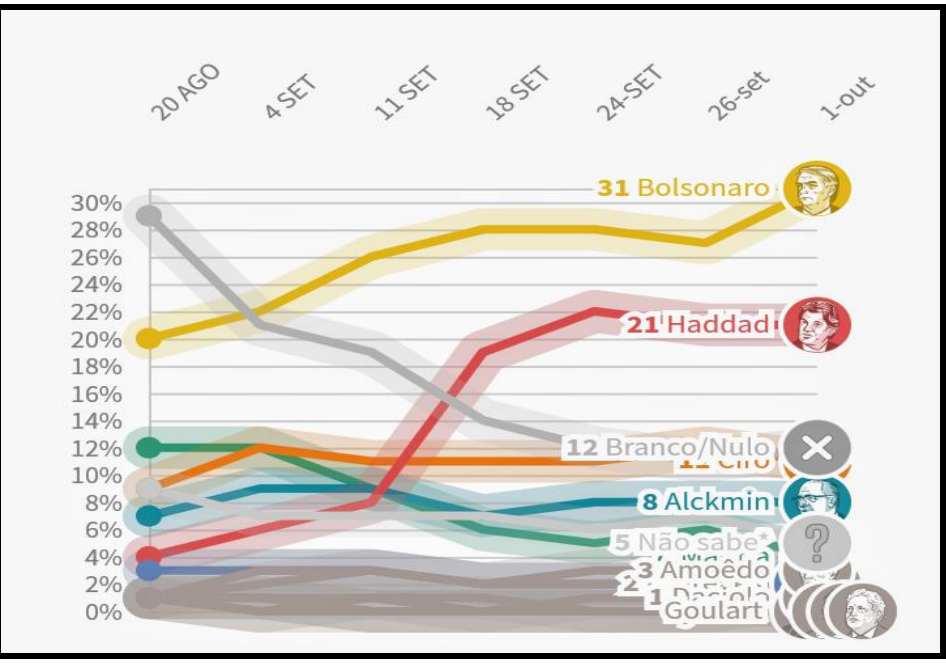

Apesar das diferenças percentuais, nas pesquisas de opinião são consenso as colocações de Jair Bolsonaro (PSL) em primeiro lugar, Fernando Haddad (PT) em segundo e Ciro Gomes (PDT) em terceiro nas intenções de votos. Sendo, portanto, os primeiros indicados pelas pesquisas nos últimos meses que antecederam as votações, em outubro de 2018. 
Figura 3 - Mapa da categorização das políticas sociais no plano de governo 2018 de Jair Bolsonaro (PSL)

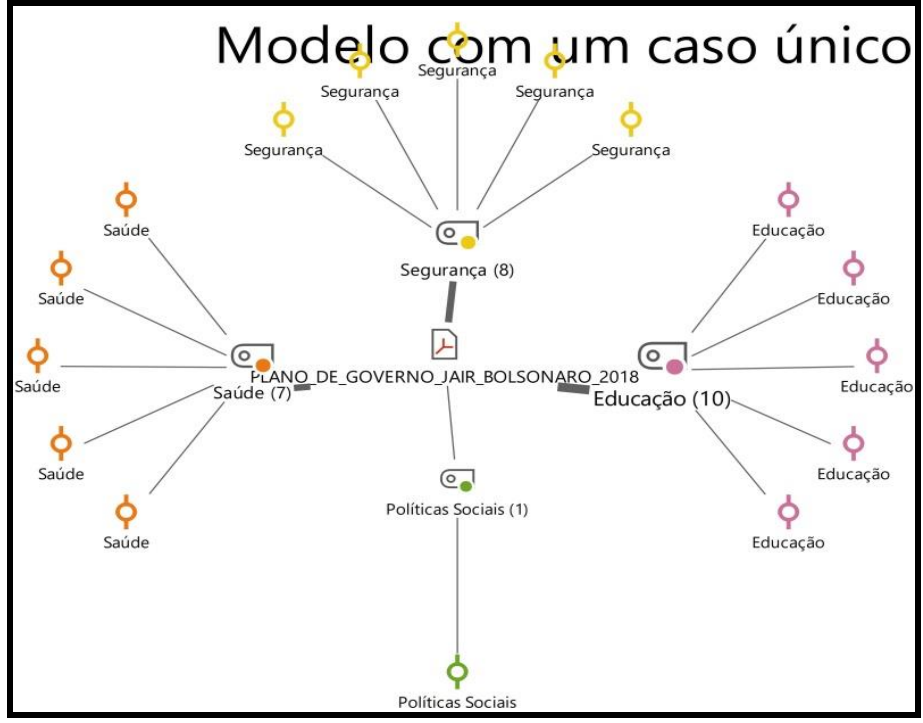

Fonte: Elaborado pelos autores, com o recurso do programa MAXQDA.

No plano de governo do presidenciável Jair Bolsonaro (PSL) foi possível verificar o quanto as políticas sociais passaram intencionalmente por um processo de invisibilidade, inércia e/ou retrocesso, ou seja, em apenas um ponto mencionou-se diretamente sobre esse eixo; das diversas proposições categorizadas há um montante de 26 itens: 10 destinados para a educação, 7 destinados para a saúde e 8 destinados para segurança. Explicitamente, apenas 1 é destinado para as políticas sociais; embora as categorias educação e saúde façam parte do foco das políticas sociais, no plano de governo não estabeleceram justificativas coerentes sobre as reais necessidades da população brasileira. 0 traço mais característico foi, de fato, a ausência de debates e proposições coerentes sobre os processos de entendimento dos contextos históricos para a inserção da população pobre aos direitos necessários, urgentes e prioritários para reforçar as ações no campo das políticas públicas.

O mapa da categorização do plano de governo de Jair Bolsonaro (PSL) é a marca da carência de prioridades às políticas sociais, em que saúde e educação não são as bases para auxiliar no desenvolvimento econômico e social. Suas proposições mostram-se fragmentadas. Sobre a segurança, o presidenciável instituiu maior interesse, talvez pelo fato de ser oriundo dos quadros do exército brasileiro, porém a intencionalidade é de instituir a segurança privada por meio de aquisição de armas.

A primazia pelo Estado gerencial e mínimo é fundante no plano de governo, uma concepção nada atual, característica de uma visão míope e completamente conservadora. Nessa perspectiva, o que se espera é uma avalanche de cortes caracterizados até por meio de contingenciamentos na área social, em específico, saúde, educação, seguridade social/previdência e 
trabalho. Destacam-se a privatização, a propriedade privada e a defesa dos interesses da classe hegemônica em detrimento dos trabalhadores.

Há características no plano de governo de uma espécie de moralismo, melhor dizendo, um falso moralismo que desconsidera os avanços sociais, desconhece a pluralidade social, a liberdade de expressão e institui o chamado combate a uma equivocada doutrinação da esquerda brasileira. 0 plano de governo apresenta-se mais por inconsistências e/ou incoerências, a acertos. Externa os princípios da acumulação capitalista de riquezas.

Figura 4 - Mapa da categorização das políticas sociais no plano de governo 2018 de Fernando Haddad (PT)

Fonte: Elaborado pelos autores, com o recurso do programa MAXDQA.

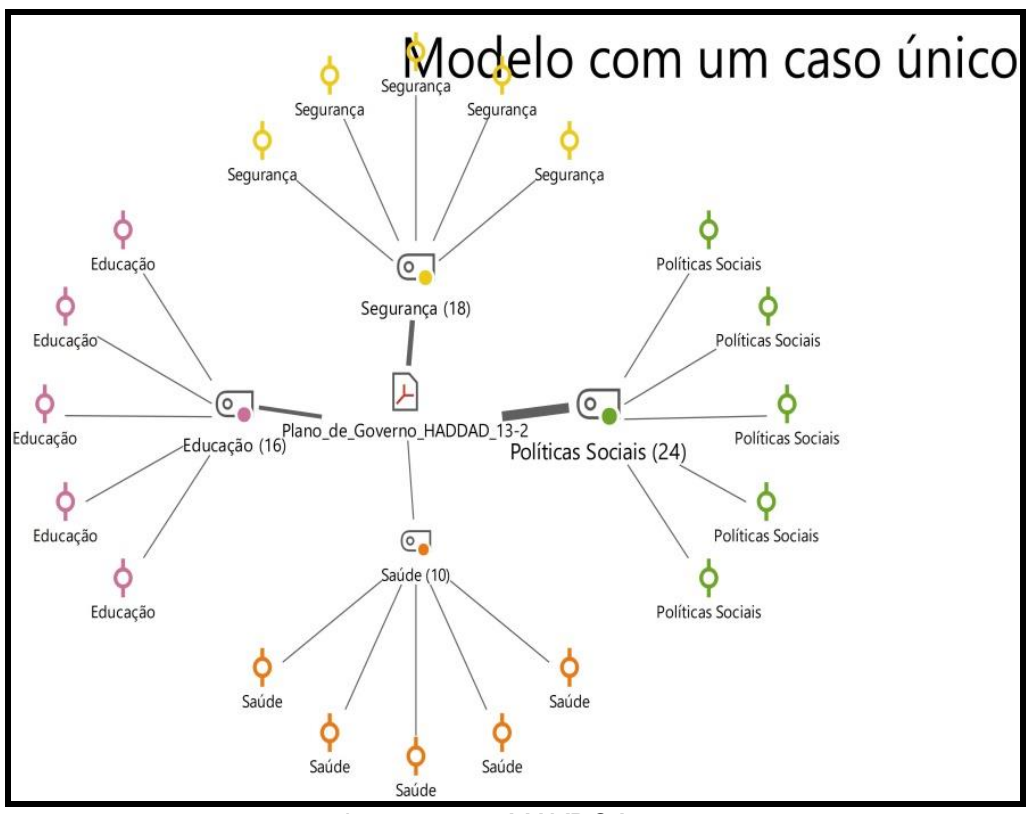

No plano de governo do presidenciável Fernando Haddad (PT), foi possível verificar o quanto as políticas sociais ganharam destaques, uma proposição que explicitou de algum modo parte significativa dos anseios da população brasileira pobre. Ao todo foram categorizados 68 itens, 16 destinados para a educação, 10 destinados para a saúde e 18 para a segurança. Especificamente sobre as políticas públicas, constatou-se 24 itens que também se vinculam à educação e saúde, aumentando o montante para 50 itens, com exceção da segurança.

Muito embora não se apresente de modo convincente a ruptura com os propósitos do Estado em sua versão capitalista, há no plano de governo de Fernando Haddad (PT) diversas características que amenizam o processo de exploração da classe trabalhadora.

Diferentemente do plano de governo do presidenciável Jair Bolsonaro (PSL), as proposições do presidenciável Fernando Haddad (PT) se aproximam de realidades diversas, algo 
característico com a própria configuração da sociedade brasileira. Mencionou-se entre as diversas reformas, a Bancária, ou seja, a prioridade de melhores adequações sobre o capital financeiro diante do país em que a pobreza já virou paisagem.

Sobre o Estado, mencionou-se a necessidade de rever sua capacidade de investimento, estatizando e combatendo privilégios patrimonialistas. A primazia é a promoção dos direitos sociais; desse modo é possível vislumbrar um equilíbrio entre as propostas do plano de governo e suas relações no âmbito das políticas sociais, tanto que o termo políticas sociais é o mais citado entre as categorias analisadas.

Figura 5 - Mapa da categorização das políticas sociais no plano de governo 2018 de Ciro Gomes (PDT)

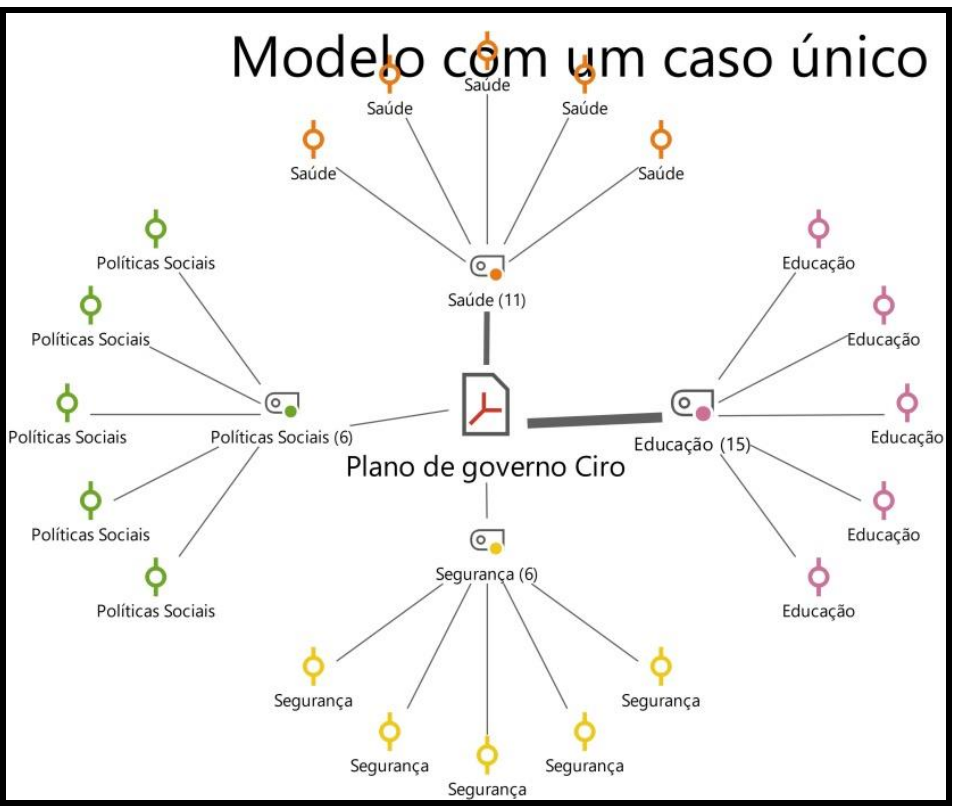

Fonte: Elaborado pelos autores, com o recurso do programa MAXQDA.

O plano de governo de Ciro Gomes (PDT) se desenha pela prioridade à educação, seguido de saúde, políticas sociais e segurança, evidenciando uma preocupação com os temas das categorias mapeadas e uma relação ponderada entre as políticas sociais dentro das propostas de governo. Ao todo forma 38 itens categorizados, dos quais 15 destinados à educação, 11 destinados para a saúde e 6 destinados para a segurança. Além disso, somam-se 6 itens mencionados sobre as políticas públicas, embora educação e saúde também correspondam ao mesmo eixo.

Uma das defesas da concepção de Estado diz respeito à ideia de que é preciso apoiar as empresas de base produtiva e recuperar a capacidade de investimento do Estado; esse eixo aponta para um dos processos de parceira público-privada (PPP). 
No programa de governo de Ciro Gomes (PDT) não se assinala (para) a ruptura do processo de produção capitalista; enfatiza-se a ideia de crescimento econômico e seus entrelaçamentos com a dignidade e soberania do povo.

As proposições de reformas estão atreladas à geração de emprego; uma delas é a reforma fiscal, tributária e previdenciária. O eixo econômico sobressai ao longo do plano de governo.

Também foi perceptível a ideia de pluralidade cultural, respeito à população LGBTI, Afrodescendentes, às mulheres, entre outros. $O$ item educação é bastante priorizado na perspectiva de manutenção e gratuidade.

\section{CONCLUSÃO}

Nesse aspecto, foi possível compreender, por meio da categorização e análise das políticas sociais apontadas nos planos de governo dos três primeiros colocados nas pesquisas de opinião, segundo as empresas de consultorias (Ibope e Datafolha) para o mandato de presidente no pleito eleitoral de 2018 (Jair Bolsonaro do PSL, Fernando Haddad PT e Ciro Gomes do PDT), que alguns planos priorizaram as políticas sociais, e seus desdobramentos entre as propostas de programas sociais, mais do que outros. Como exemplo, verificamos que o plano de governo do candidato Jair Bolsonaro apresenta diretamente apenas 1 categoria de políticas sociais, o plano de Fernando Haddad apresenta diretamente 24 categorias de políticas sociais e o plano de Ciro Gomes apresenta diretamente 6 categorias de políticas sociais.

Por meio do recurso do Software de análise de dados qualiquantitativos MAXQDA estabeleceram-se as categorias para verificar as possíveis discrepâncias entre os planos de governo sobre o eixo e os desdobramentos das políticas públicas. Foi possível, portanto, vislumbrar os temas prioridades apresentados pelos presidenciáveis para o enfrentamento das mazelas que acometem os variados segmentos da sociedade brasileira na atualidade.

As condições precárias de acesso a bens e serviços geridos pelo Estado têm reproduzido o desemprego, extrema violência, habitações em áreas de risco, mortalidade infantil, entre outros. Daí a importância de se analisar os planos de governo para melhor compreensão das potencialidades de criação e efetivação de políticas públicas para o povo e com o povo.

Pensar o planejamento de como as demandas sociais serão contempladas num governo presidencial é de extrema importância, pois esclarece a primazia dos interesses políticos que permeiam esse contexto, e como se pretende sanar problemáticas que dificultam e/ou atravancam o acesso da população a serviços básicos nessa conjuntura, num interminável ciclo deficitário do acesso restrito às políticas sociais. 
Os planos de governo à presidência são o cerne do trabalho que contemplará as principais ações políticas em um país. É um contrato, um acordo, uma responsabilidade assumida pelo candidato junto à população e ao Estado que se pretende governar. Porém, o que se observou foi a secundarização desse documento (plano de governo) diante da polifonia midiática de produção e disseminação de Fake News entre a população, antes e durante o processo eleitoral, o que trouxe, de fato, prejuízos sem precedentes ao país em toda a sua diversidade, possibilidade e necessidade de mudanças para agregar a classe trabalhadora no processo de produção e distribuição de renda, além de garantias de acesso e permanência nas diversas modalidades de educação, sistemas de saúde, sistemas de segurança, entre outros.

Assim, analisar e compreender como as políticas sociais se apresentam nos planos dos presidenciáveis e como as mídias em suas representações nas redes sociais podem e influenciaram na escolha de um candidato é fator importante. Quando se deixa de lado a prioridade de analisar os planos de governo, pode-se escolher um candidato a presidente do Brasil que nem sempre apresentou traços característicos na defesa e engrandecimento do Estado máximo, forte e garantidor das políticas públicas existentes e proponente de novas políticas públicas; e que, tampouco, é defensor dos princípios básicos que asseguram a cidadania.

Instaurou-se no Brasil, nas eleições de 2018, um processo de falsa compreensão dos aspectos políticos, que muitas vezes se mostrou errôneo, baseado em falsidades e com excessivo crédito ao senso comum, uma festa regada a Fake News.

É de essencial relevância a constante busca de saídas racionais para desvelar os interesses políticos e econômicos que emergem desse contexto de disseminação de inverdades na versão de uma figura atípica que se denominou como mito, ilusória em sua versão para os tempos atuais que se configurou, segundo Vernant (1986), na condição de causador de espantos, de medos e destruições, objetivamente poderá executar o plano de aniquilamento dos direitos sociais na vertente das políticas públicas, ou seja, haverá perdas políticas e sociais historicamente conquistadas sem precedentes. Afinal, qual foi o candidato escolhido pelas urnas na condição de presidente do Brasil no pleito de 2018? As ideias e ações do presidente do Brasil são novidades para você nos dias de hoje? Lembre-se de que o plano de governo do então candidato a presidente do Brasil, no pleito de 2018, já apontava os traços de uma conduta externada para além das Fake News.

\section{REFERÊNCIAS}

BOGDAN, R.; BIKLEN, S. Investigação qualitativa em educação: uma introdução à teoria e aos métodos. Porto: Porto, 1994.

DATAFOLHA INSTITUTO DE PESQUISAS. História. São Paulo, 2018. Disponível em: ]http://datafolha.folha.uol.com.br/sobre/historia/index.shtml. Acesso em: 7 out 2018. 
FALEIROS, V. de P. O que é política social. São Paulo: Brasiliense, 2006.

GAZETA DO POVO. Eleições 20108: candidatos a presidência do Brasil. Curitiba, 2018. Disponível em: https://especiais.gazetadopovo.com.br/eleicoes/2018/candidatos/presidente/. Acesso em: 7 out. 2018.

GIBBS, G. Análise de dados qualitativos. Porto Alegre: Artemed, 2009.

GIELOW, I. Bolsonaro e Haddad se enfrentarão no segundo turno. Folha de São Paulo, São Paulo, 2018. Disponível em: https://www1.folha.uol.com.br/poder/2018/10/bolsonaro-e-haddad-se-enfrentaraono-segundo-turno-projeta-datafolha.shtml. Acesso em: 8 out. 2018.

GRAGNANI, J. Fake news nas eleições de 2018: um Brasil dividido e movido a notícias falsas, uma semana dentro de 272 grupos políticos no WhatsApp. BBC News Brasil, Londres. 2018. Disponível em: https://www.bbc.com/portuguese/brasil-45666742 Acesso em: 5 out. 2018

IBOPE INTELIGÊNCIA. Institucional. [S. I.]: [2018]. Disponível em: http://www.ibopeinteligencia.com/institucional/ibope-inteligencial. Acesso em: 7 out. 2018.

SADI, A. Aliados pressionam Haddad para que ele abandone a agenda "Lula Livre"; Bolsonaro reforçará discurso anti-PT. G1, [S. I.], 2018. Disponível em: https://g1.globo.com/politica/blog/andreiasadi/post/2018/10/08/aliados-pressionam-haddad-para-que-ele-abandone-a-agenda-lula-livrebolsonaro-reforcara-discurso-antipt.ghtml Acesso em: 8 out. 2018.

SECCHI, L. Políticas públicas: conceitos, esquemas de análise, casos práticos. 2. ed. São Paulo: Cengage Learning, 2013.

VERNANT, J.-P. La mort dans les yeux: figura de l'Autre en Grèce ancienne. France: Hachette Pluriel Editions, 1986.

Notas:

${ }^{1}$ A exemplo da Folha de São Paulo online, G1, BBC News, entre outros.

2 Segundo o próprio site, o DAFOLHA foi criado em 1983, ainda como departamento de pesquisas e informática do Grupo Folha da Manhã, com o objetivo de oferecer conteúdo e servir como ferramenta de planejamento para o Jornal Folha de São Paulo e outros veículos e serviços da empresa.

${ }^{3}$ Fundado em 1942, o Instituto de Opinião Pública e Estatística (IBOPE), visa fornecer informações por meio de pesquisas acerca de opiniões púbicas de determinado assunto, como eleições, e se definem: "[...] somos admiradores do comportamento humano. Há mais de sete décadas observamos, descrevemos, medimos e monitoramos esse rico, diverso e mutante universo que forma a América Latina."

40 "MAXQDA" The Art of Data Analysis, é um software qualiquantitativo para análise de diversas fontes de pesquisa. Segundo Gibbs (2009, p. 145) ajuda na "[...] armazenagem e manipulação de textos e documentos e à criação e manipulação de códigos". Como um dos pioneiros no campo (a primeira versão foi lançada em 1989).

${ }^{5}$ Está relacionado à priorização do Estado Liberal em atender as necessidades econômicas do mercado em detrimento das demandas sociais, contudo educacionais, levando este sistema a um fracasso sistêmico que não corresponde às necessidades emancipatórias humanas, gênesis da das políticas sociais.

${ }^{6}$ Para Sechhi (2013), os atores políticos são aqueles que têm capacidade de influenciar, direta ou indiretamente, o conteúdo e os resultados da política pública, aos quais cita oito principais categorias: políticos, designados politicamente, 


\section{AS POLÍTICAS SOCIAIS NOS PLANOS DE GOVERNO DOS PRESIDENCIÁVEIS 2018 NO BRASIL E A MÍDIA}

burocratas juízes, grupos de interesse, partidos políticos, meios de comunicação, policitakers e organizações do terceiro setor.

${ }^{7}$ Período referente ao Governo Presidencial brasileiro de Fernando Henrique Cardoso.

8 Os debates aconteceram entre os presidenciáveis durante o primeiro turno. No segundo turno das eleições, que foram decididas entre Jair Bolsonaro (PSL) e Fernando Haddad (PT), não aconteceram debates devido ao candidato do PSL se recusar a participar dos diversos convites para expor e até mesmo confrontar suas propostas de governo/eleitorais.

${ }_{9}^{9}$ As pesquisas de opinião mostraram pequenas margens de erros; assim, não foram divulgadas com percentuais totalmente iguais.

10 Alguns meios de comunicação deram ênfase a determinados candidatos em detrimento de outros, inclusive veiculando suspeitas de corrupção de partidos ligados aos candidatos, ou a determinado candidato no momento da divulgação dos resultados, entre outras estratégias midiáticas.

11 Traduzido para o português brasileiro como Notícia Falsa.

12 Referente ao movimento dos partidos de direita contrários ao Partido dos Trabalhadores (PT), fomentado pelas mídias sociais brasileiras nos últimos anos.

$13 \mathrm{Na}$ história da sociedade brasileira, principalmente no período republicano, por um lado ocorreu a conquista de direitos, por outro a concessão. Há alguns exemplos: licença maternidade, carteira de trabalho, salário mínimo, estabelecidos por meio das constituições de 1934, 1937, 1946, 1967 e 1988. 